\title{
A Review of Intrinsic and Extrinsic Motivations of ESL Learners
}

\author{
Chiew Fen $\mathrm{Ng}$ and Poh Kiat $\mathrm{Ng}$
}

\begin{abstract}
Motivations, both intrinsic and extrinsic, are key factors in the success of learners at all stages of their education. The learners themselves and teachers or parents play a pivotal role in providing and encouraging that motivation in the learning and teaching environment. All learners are motivated differently and it takes time and a lot of effort to get learners to build their enthusiasm for learning, working hard and pushing themselves to excel. However, how do we know the learners are motivated? This review paper will answer the question accordingly by looking at some areas; 1) roles of intrinsic and extrinsic motivation in second language learning, 2) describing teachers' motivational practices and their learners' motivation and 3) identifying other possible factors to enhance learners' motivation in $\mathbf{L} 2$ learning. These areas covered in this paper are based on theories and findings discussed in previous studies on motivation of $L 2$ learners. A brief discussion and some beneficial implications for teachers and learners are also included. This review concludes that L2 learners' motivation (intrinsic motivation) and the effect of perceived levels of teachers' commitment (extrinsic motivation) reconfirms that a teacher influences his/her learners' motivation. Furthermore, the learners' levels of proficiency may be an important factor which can determine the effectiveness of teaching strategies as a motivator for learners. This review also concludes that motivation is a crucial factor in learning the second language and is influenced by variables like personality and attitudes of learners, learning styles and power relationship between languages.
\end{abstract}

Index Terms - Intrinsic motivation, extrinsic motivation, L2 learners, motivational strategies.

\section{INTRODUCTION}

Motivation has been widely accepted as one of the key factors that influence success in second/foreign language (L2) learning. Motivation is known as a stimulant for achieving a specific target [1]. According to Gardner's theory [2], motivation can be referred to a kind of central mental engine or energy-centre that includes effort, want or will (cognition) and task-enjoyment (affect). Motivation provides the primary momentum to initiate L2 learning and all the other factors involved in L2 acquisition presuppose motivation to some extent. Without sufficient motivation, even individuals with the most remarkable abilities cannot accomplish long-term goals, and neither are appropriate curricula and good teaching

Manuscript received April 3, 2015; revised June 21, 2015.

Chiew Fen $\mathrm{Ng}$ is with the Faculty of Modern Language and Communication, Universiti Putra Malaysia, 43400 Serdang, Selangor Darul Ehsan, Malaysia (e-mail: kilaga@gmail.com).

Poh Kiat $\mathrm{Ng}$ is with the Faculty of Engineering and Technology, Multimedia University, Jalan Ayer Keroh Lama, Bukit Beruang, 75450 Malacca, Malaysia (e-mail: pkng@mmu.edu.my). enough on their own to ensure learner achievement. If we are discussing motivation, the two terms which are synonym with it are intrinsic and extrinsic motivation. These two types of motivation will be the main focus in this review paper.

Intrinsic motivation can be found within the individual and is related to the individual's identity and sense of well-being. Learners are intrinsically motivated when learning is a goal in itself. Intrinsic motivation was strongly reflected in early definitions of L2 motivation. It is defined as "the extent to which the individual works or strives to learn the language because of a desire to do so and the satisfaction experienced in this activity" [3]. They find intrinsically motivating tasks interesting and challenging; the reward is the enjoyment of the activity itself or a feeling of competence (self-efficacy) in doing the task [4]. In such tasks, learners may experience flow, an in the moment, optimal sensation of enjoyment and competence [5] that has yet to be sufficiently explored in the L2 field.

Extrinsic motivation comes from outside the individual. Learners are extrinsically motivated when learning is done for the sake of rewards such as grades or praise that are not inherently associated with the learning itself, that is, when learning or performing well becomes necessary to earning those rewards. A number of researchers and theorists [6] have contended that intrinsic motivation correlates more closely with language learning success than extrinsic motivation, but a learner's total motivation is most frequently a combination of extrinsic and intrinsic motivation. External rewards can either increase or decrease intrinsic motivation, depending on how they affect self-efficacy [7].

This review paper aims to identify roles of intrinsic and extrinsic motivation in second language learning and to describe teachers' motivational practices and their learners' motivation. Besides that, it also aims to find out if there might be other possible factors to enhance learners' motivation in L2 learning.

\section{APTITUdE, MOTIVATION, AND GARDNER'S SOCIO-EDUCATIONAL MODEL OF SLA}

Gardner and Lambert [8] found that aptitude and motivation were the two factors most strongly associated with learners' L2 achievement. L2 learners with positive attitudes toward the target culture and people will learn the target language more effectively than those who do not have such positive attitudes [9]. The learners who are not motivated are more likely to fail in achieving their goals than those learners who are motivated. This issue has been discussed based on the role of L2 learning motivation studied by social psychologists and the Gardner's Socio-educational model of SLA. Gardner 
and MacIntyre [10] argue that the model shows the importance of what takes place in the learning contexts: "Teachers, instructional aid, curricula, and the like clearly have an effect on what is learned and how learners react to the experience." Fig. 1 shows the representation of socio-educational model of SLA. The model also predicts that learners' degree of success affects their feelings and that both terms; success and feeling will have an influence on individual-difference variables including language attitudes and motivation.

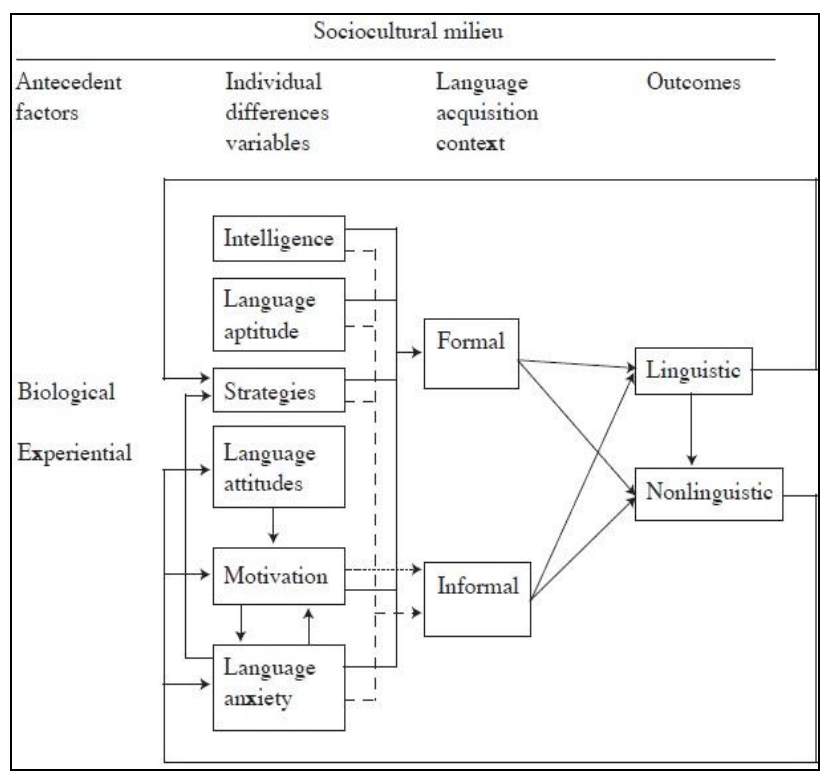

Fig. 1. Representation of socio-educational model of SLA [10].

The issues of present in motivation of L2 learners will be discussed further in the next section of this paper. It focuses on intrinsic motivation and language learning development, ways to maintain that type of motivation for L2 learners, how extrinsic motivation affects learners' in learning environment, the motivational strategies, and parental roles in language learning motivation.

\section{How INTRINSIC MOTIVATION HELPS THE LEARNERS' LANGUAGE LEARNING?}

L2 intrinsic motivation involves enjoyment of learning a second language for its own sake without any external pressure. According to Noels, et al. [11], there are three types of intrinsic motivation based on Self Determination Theory [12] and the empirical studies by Vallerand [13]. The three types of intrinsic motivation are knowledge, accomplishment and stimulation. Knowledge can be defined as motivation for learning L2, exploring new ideas and developing knowledge while accomplishment refers to the attempt to master a task or to achieve a goal [14]. Stimulation is related to motivation based on stimulation of performing the task, such as aesthetic appreciation, fun or excitement.

As a teacher if we want to see accelerated language learning we think it is important that we try to find ways to tap into what motivates learners and help them to stay motivated. As we believe motivation is one of the key aspects to successful language learning. Some researchers believe that intrinsic motivation is one for which there is no apparent reward except the activity itself which aims to bring about certain internally rewarding consequences such as competence and self-determination are superior to extrinsic motivation. We can see in real classrooms that often learners who are just beginning would be highly motivated on their first few classes or lessons and they are very keen to learn English [15]. However after some time and usually once they attain good level of communication in English, their level of motivation would decrease, their rate of language acquisition declined and slowed, and sometimes their behavior and attitude towards the class or language decreased as well. While some learners remained highly motivated to learn English and continued to do well, it was quite difficult to encounter such a situation.

In some studies revealed, most of the learners had extrinsic (outside of themselves) motivation to learn English often because their parents wanted them to learn. The learners that remained highly motivated often had their own intrinsic motivation for learning rather than just extrinsic factors. For example one learner in an English classroom who really wanted to get into the Malaysian police force had to achieve a good level of English. His parents were not keen on letting him pursue his ambitions of being a policeman. He remained motivated for a long length of time and made really great language learning progress but eventually even his motivation began to fade. At this point, it should be the teachers who need to take the role in reinforcing motivation in learners. When the teacher approached the student for feedback, the situation revealed that he no longer was sure of pursuing his ambitions and his dream to follow the footsteps of his grandfather. Living away from his family had opened up new possibilities and exposed him to different cultures and a different world view. The teacher tried to help him to discover new reasons within himself for learning English. His behavior and motivation increased but it didn't return to the previous high level.

Based on that case, we could see that every teacher knows that motivation is the key but how many of us actually take the time to think deeply about it and to ask deeper questions about our learners. We should particularly do this with the language learners we have concerns about or whose learning is beginning to slip. Before we can do this we need to take time to find out what really motivates our learners. Such data could be gathered initially through a survey with some follow up on discussion. Motivation is a powerful tool that we can explore and utilize further in our teaching. Researchers have also concluded that teachers are one of the most determinant factors of L2 learners' motivation [16], [17]. L2 teachers play one of the most influential roles to help their learners engaging and persisting in the long process of SLA. Among the role that teachers play are as initiator, facilitator, and motivator, ideal model of the target language speaker, mentor, consultant, and mental supporter. These roles are assumed to influence each learner's motivation.

\section{WAYS TO MAINTAIN LEARNERS INTRINSIC MOTIVATION}

There are some ways to help maintain and increase learner intrinsic motivation in together with other factors in assisting 
the learners with their language learning development. Firstly, involve learners in some decisions on related programme, issues, or interest, create a safe classroom environment, a supportive atmosphere for learners in the class with mutual trust and respect and with low levels of anxiety and stress. Learners should be encouraged to express their opinions and perspectives on different issues because they feel safe and protected from embarrassment and sarcasm. This could be as a strategy of maintaining learners' motivation and avoiding of lose of interest, get distracted and bored of activities. Therefore, it needs some kind of stimulation and foster learners' autonomy [18].

Teachers and peers interact with learners on a personal level and show that they care about learner's personal issues and challenges that they face in the classroom and outside the classroom. Secondly, develop a sense of community and promote a sense of belonging and be enthusiastic. Enthusiasm is contagious in classrooms; therefore, if learners recognize their teacher's enthusiasm to the task, they will be enthusiastic as well. Thirdly, make language learning enjoyable and interesting: texts, audiovisual, ICT materials, tasks, and class activities should be related to learnes' interests and culture.

Furthermore, teachers should give learners choices in assigning a task, and learners' preferences should get priority. Elements such as music and humour can be incorporated in teaching to add fun to a lesson. Fourth, make the teaching materials relevant to the learners. Provide material that will assist them to succeed in the mainstream classroom and in their world beyond the school ground. Motivation to learn decreases dramatically when the learners do not see any relevance to their lives. Fifth, involve the learners in setting their own learning goals and use "assessment for learning" strategies pre and post the lesson. This helps them to think about their learning and be more connected to it. Make sure teacher feedback is specific and linked to the learning goal.

Next, set challenging tasks but scaffold them to success can also be the way to maintain the learners motivated. Learners will have a greater tendency to do an activity if they feel they will succeed in that particular activity. Hence, it is unlikely to aim for something if we know that we will eventually fail. The simplest way to ensure that learners expect success is to make sure that they achieve it constantly. This suits with the study done by Sakai and Kikuchi [19] which regard the learning contents and materials were factors of their demotivation. This is due to the content and materials used in classrooms are not achieving learners' learning goals, so it gives an impact on their intrinsic motivation [18]. The tasks should be challenging yet suitable and achievable to learners' ability and expectation.

Besides that, the use of pair and group work for learning language is close collaboration and communication among learners is in itself motivation and provides more opportunities to practice using language. Lastly, help learners create realistic beliefs about language learning. Some learners bring some unrealistic learning beliefs about how much progress or learning they can achieve in a term or year. If they do not see that their beliefs or expectations achieved, they will become disappointed and lose interest. Teachers, therefore, should explain the complexity of learning a second language and help them to see the progress that they are making.

\section{How Can Teachers Promote Motivation IN THE ESL/EFL CLASSROOM?}

The teacher is a complex and key figure who influences the motivational quality of learning [20], and plays a pivotal role in mediating the growth of motivation [21]. The English language is taught in school just for a few hours a week in schools or institutions but it has a big role as a medium of communication. Therefore, classroom experience will be one of the influential determinants for the quality of learners' learning experience, which in turn will affect their motivation. The teacher is the prime source of the new language, in contrast with the natural setting where exposure is often genuinely situational. Indeed, Acknowledging the importance of classroom teacher, in the field of L1 instructional communication. For example, several studies investigating teacher impact on changes in learner motivation have been carried out by Christophel and Gorham [22] and Gorham and Christophel [23], all of which found significant positive and negative influence on learner motivation. For example, Christophel and Gorham [22] found that the teacher's use of immediacy behaviour, which means "the perceived physical and/or psychological closeness between people" [24], influences learners' motivation in the following way: Teacher's appropriate use of immediacy behaviours positively affects learner motivation whereas the lack of learner motivation is attributed to teacher's inappropriate use of them.

Many studies on motivation also conclude that L2 teachers play one of the most influential roles to help learners engage and persist in the long process of SLA [17], [19], [25]. The 'magic' strategies that have been used by teachers in classrooms so far are actually aim for a few things which are to motivate the learners in their learning, to show the learners the benefits of learning L2, to create a safe, welcoming teaching-learning environment, and to develop learners' realistic intrinsic motivation. Based on that reasons, we could see that the teacher's practices on motivation are indirectly influence on learners' intrinsic motivation and the teaching skills should be fostered to enhance the teachers to ask questions and provide feedbacks. This implementation indirectly gives intrinsic motivation to the learners [26].

Because of the importance of the nature of the interactions that occur between learners and teachers, many studies have been dedicated to the discussions of the influence of teachers in the process of foreign language learning. According to Veronica [27], the important qualities of a good teacher usually displays in the class is enthusiasm, acknowledgement and stimulation of learners ideas, the creation of a relax and enjoyable atmosphere in the classroom, the presentation of activities in a clear, interesting and motivating way, the encouragement of learners with difficulties, helping them to increase their expectations of themselves.

In an article published in 1982, Finocchiaro and Brumfit [28] have added to all these the importance of (a) making sure the learners comprehend every dialogue, utterance, the gist of the reading passage; (b) giving them extensive practice in using verbal or non-verbal alternatives for communicative expressions, structures or language items; (c) correcting important errors tactfully by rephrasing a question, expanding an answer, or by merely saying "listen" and giving the correct 
answer; (d) letting them either grade their own papers or do so with a partner; (e) showing concern for school or community problems of individuals; (f) making it possible for them to enjoy small successes and the feeling that they are making definite - even if slow - progress toward their goals.

As Finocchiaro and Brumfit [28] argue in points (c), (d), (e), the problem of error correction plays a very important role in the process of motivating or de-motivating learners. Being constantly aware that all human learning is fundamentally a process involving the making of mistakes may help any teacher in using mistakes and errors creatively during the teaching activity, for they hold in them some of the keys to the understanding of the process. When teachers help the learners to develop an internal sense of control as well as feelings of effectiveness in their ability to carry out tasks, then there are great chances for the learners to become motivated to learn. External reinforcers in the form of rewards, good marks or simple praise, are often considered to be excellent ways of motivating underachieving or reluctant learners. Conversely, extra homework, punishment or other sanctions, proved not only ineffective in bringing about positive change, but also having exactly the opposite effect.

As Williams and Burden [29] have rightly observed when "feedback actually provides information to learners that enables them to identify specific aspects of their performance, it should prove both motivating and helpful to them to move into the zone of next development. If, on the other hand, the feedback fails to provide this kind of information, it could have entirely the opposite effect".

\section{TEACHERS' MOtIVATION STRATEGY}

As mentioned in previous sections, teachers play a pivotal role in promoting motivational qualities in their learners. In fact some studies in the past have investigated the relationship between motivational variables and L2 achievement using various measures of motivation. As cited by Bernaus and Gardner [30] from Gardner's own work in the 1980s and 2006, some studies have based models on the socio-educational model of SLA and the Attitude Motivation Test Battery, some on self-determination theory model, such as the version that Noels [31] adapted from the self-determination theory of Deci and Ryan [12], or on the social context model of Clement [32] Despite the various use of models in these studies, it was reported that all these studies had findings that established relationships between motivation and L2 achievement. However, such studies have been criticized for its focus on individual difference correlate of language achievement without considering the contributions and importance of the teacher in the learning process of learners in class. More recently, it has been acknowledged that approaches which are more education-friendly can help teachers gain better understanding of learner motivation and have a better hand in promoting its development and supporting maintenance in class.

There is a general belief that a teacher is able to enhance learner motivation when he or she employs the use of motivational strategies in a class. The term motivational strategies refer to two aspects, in which the first is the instructional interventions a teacher utilizes in order to encourage learner motivation and the second, bears reference to the self-regulating strategies employed by individual learners with the intention to control the level of their own motivation [33]. In this review, the term motivational strategies refers to the former definition.

The belief in which the teacher plays a key role in promoting learner motivation has led a number of researchers and educators to suggest means of supporting and developing motivation in learners. Researchers such as Dornyei and Csizer [34] conceptualized the 10 commandments for teachers which main focus were meant for improving learner motivation. Others such as Williams and Burden [29] developed 12 suggestions for motivating learners. It is apparent that the notion fundamental to all of these suggestions is that teacher behaviour and beliefs can have a direct effect on learner motivation and have a direct influence on the learners.

Over the years there have been many motivational teaching practices that teachers have employed to keep their learners motivated in class, among them commonly used by language teachers, the carrot-and-stick approach which usually involves reward and punishment. However, these techniques lacked a framework that could uphold them theoretically for further research and study.

\section{A FRAMEWORK FOR MOTIVATIONAL STRATEGIES}

As explained in the previous section, motivational teaching practices lacked a theory-based framework. The only attempt to systematically classify motivational strategies utilized by teachers to date was by [24]. Dornyei [24] proposed that these strategies for supporting the development of motivation could be categorized into four main groups or dimensions.

The first category consists of components that address the classroom condition. In creating basic motivational conditions, it is necessary that teachers practice appropriate behaviours such as promoting good relationships with learners, maintaining an atmosphere that is pleasant and supportive in class, and facilitating group norms to promote a cohesive learner group.

The second category is directed to build learner motivation or creating learner initial motivation by helping learners improve their language-related values and attitudes, enhancing their goal orientation, planning a curriculum that is relevant, and building realistic learner beliefs.

The third category entails the maintenance of motivation through proximal setting of subgoals, enhancing the quality of the learning experience, raising learner self-confidence, generating learner autonomy, and encouraging learner strategies that are self motivating. Teachers protect and maintain learner motivation through tasks which are stimulating, enjoyable and relevant to the lesson [33].

The fourth category concerns promoting positive self-evaluation by encouraging acknowledgment to effort instead of attribution to ability, giving effective and encouraging motivational feedback, enhancing learner satisfaction and offering grades in manner of motivation [30], [33]. 
Fig. 2 represents a diagram on the Components of a Motivational L2 Teaching Practice that represents the concept of motivational strategies by Guilloteaux and Dörnyei [33] which indicates the main macro-strategies related to each category.

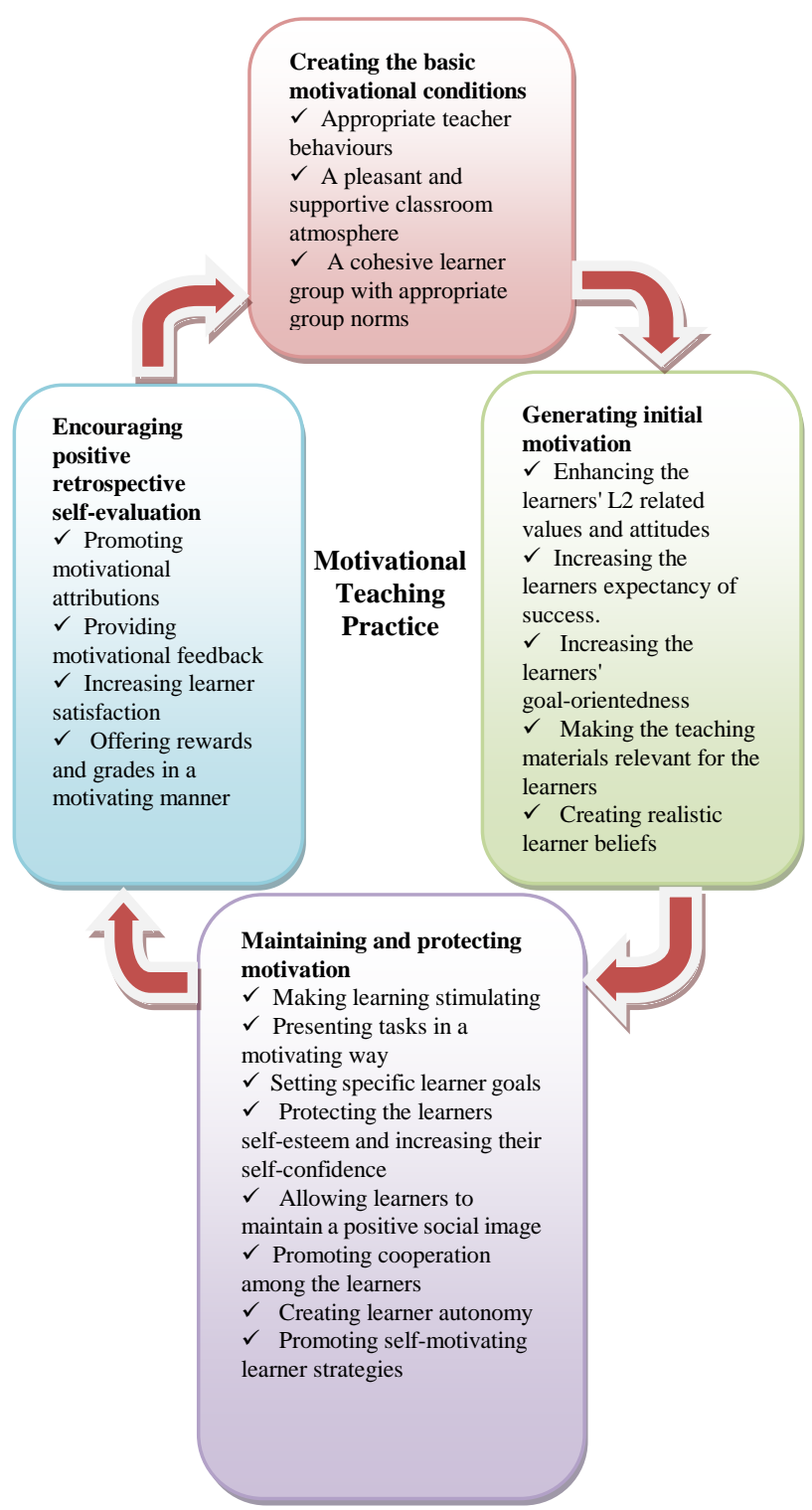

Fig. 2. Components of a motivational L2 teaching practice [33].

The development of Dornyei [20] model has led to research that looks into the relationship between teachers' motivation teaching practice and the language learning motivation of learners. A study that specifically examined this link was conducted by Guilloteaux and Dörnyei [33]. Their study involved the investigation of 40 ESOL classrooms in South Korea and an observation of classrooms consisting 27 teachers and more than 1,300 learners [30], [33]. Learner motivation was evaluated through a self-report questionnaire and a classroom observation instrument known as the motivation orientation of language teaching (MOLT) was developed specifically for the investigation of the study. The same instrument was used for teachers when researchers assessed the motivational strategies employed by teachers, alongside a posthoc rating scale rated by the observer. The study used a class as a defining unit for all analyses performed.

Results from the study revealed that there is an obvious link between motivational teaching practice and the language learning motivation of the classes. Even though the researchers of the study did not examine the link between teacher's motivational teaching practices and language achievement of the classes, they claim that research that attempts to confirm the application of teaching practices that transforms into better levels of achievement will be of great use [35].

In another study by Bernaus and Gardner [30], results revealed that the language achievement of the class showed no relation to the motivational strategies use reported by the

teachers but it showed relation when it is reported by the learners. The inconclusiveness of the link between motivational teaching strategies and language learning shows the intricacy of the issues implicated in the nature of this research [35].

\section{PARENTAL ENCOURAGEMENT IN LANGUAGE LEARNING MOTIVATION}

According to Dornyei [16], motivation in language learning is affected by various external influences such as the school environment which constitutes factors such as teachers, peer-groups and instructional material. However, social and contextual factors such as immediate family and friends also have an effect on motivation. These factors that make up learners' immediate environment play a critical part in learners' practice of setting goals, forming attitude towards learning, influencing their own self-efficacy beliefs in learning and determining the effort and persistence in accomplishing a learning activity. Researchers identified the influence of this environment on language learning as influence of parental encouragement and praise on student's motivated behaviour in his initial research [3], [8], [36].

The emergence of this new construct revolutionized the way researchers of viewed motivation in language learning. Following Gardner's recognition of parental encouragement as a construct in the socio-educational model, researchers have considered factors such as the role of significant others [29] and the learners' family [31] in their own motivational model. This subsequently led numerous researchers such as Atay and Kurt [37], Csizer and Dornyei [38], Csizer and Kormos [39] and many more to adopt the construct in their own research [40].

As cited by Wilson [41], Gardner [2] posits that parental influence can be categorized into two forms of encouragement which is active or passive. Parents who provide the active form of encouragement can provide positive or negative parental influence toward their children's language learning experience. Basically parents who encourage and reward their children's language learning are perceived as taking up an active role with a positive impact while parents who express negative attitudes towards the people or groups of the L2 community and discourage L2 learning take an active role but with a negative impact.

Parents with passive roles however, promote their children's desire to align with the speakers of the language 
through their attitude toward the L2 community. This according to Gardner [3], reflect an integrative orientation [3], [41], [42]. A negative parental attitude toward the L2 speaking community would have an impact on their children's attitude and would not give necessary opportunity for motivation to develop. Gardner [2] asserts that parents who may or may not be aware of the usefulness of language learning are likely to pass that attitude on to their children; even though they might view its usefulness regarding a specific aspect such as being able to enter a college or university or obtaining good grades.

One such study that exemplifies the aforementioned researchers' views is from Bartram [42]. In his research, Bartram [42] had studied the influence of parents on the attitudes toward the language learning of 411 learners of French, English and German. The researcher examined the various ways in which parents exerted influence in their children's learning of a foreign language. The findings of the study revealed that the German learners' positive attitudes and the more negative attitudes of the English learners conformed to their parents' attitudes. The results from this study presented verification of a relationship between learners' attitudes and their parents [43].

In another study, a group of researchers conducted a research on 190 South Korean high school learners in which the researchers used a 55-item questionnaire to measure attitudes toward English speakers and their communities and atttitudes toward the English-speaking culture, motivation intensity, the desire to learn and their attitudes toward the learning English, amotivation, parental involvement which comprised of active parental encouragement, passive parental encouragement and parental pressure, parental disinterest and learners' competence in L2 [43].

The findings of the study revealed that South Korean learners who experienced more pressure to perform reported having parents who encouraged them actively and passively. It was also reported that the less learners reported parents' disinterest, the more parents encouraged them passively. Researchers also found that learners estimated more effort in their work when parents applied more pressure to their children. Parents who perceived their children as not being interested in learning English and showed little or no interest in their children's language learning possibly corresponded with the nonexistence of goals set by their children.

The researchers concluded that parental encouragement that is active presented a certain relationship with the levels of attitude, motivation and motivation in learners. This was not surprising as in the context of South Korea where society is education-centred; parents are constantly being actively involved in their children's education.

\section{The IMPORTANCE OF TAKING Changes IN Motivation}

The importance of taking changes in motivation into consideration has been strongly advocated by Dornyei [44] who stated that 'during the lengthy process of mastering certain subject matters, motivation does not remain constant but is associated with a dynamically changing and evolving mental process, characterised by constant (re) appraisal and balancing of the various internal and external influences that the individual is exposed to'. The learners tend to shift the importance in teacher-related factors from personality-based ones to teaching skill-based ones as they develop their proficiency. This may be one of the reasons for the phenomenon that Jacques [45] noted that 'some classroom practitioners often discover that some activities just don't seem to hit the mark with some language learners'. This supports what Dornyei and Csizer [34] concluded when they stated that 'no motivational strategy has absolute and general value because such strategies are to be implemented in dynamically changing and very diverse learning contexts, in which the personality of the individual learners and the teacher, as well as the composition and structure of the learner group, will always interplay with the effectiveness of the strategy'.

Personal traits may inhibit progress in language learning. According to Rivers [46], these personal traits such as fear or anxiety may combine with learned social motifs such as a desire for status in a group. An anxious learner may try hard to catch up with the group and acquire proficiency in a language. A friendly/supportive environment may be decisive in such a situation. But the judgement of classmates can also be harmful, destroying the self-belief in one's ability to succeed. Combined with a generalized fear of negative evaluation, it may inhibit or distract the learner from the task of attending and remembering new items.

Another factor that able to enhance learners' motivation in L2 learning is the individual learners' feelings of competence and self-efficacy. Displaying no signs of inhibition, they are usually eager to take risks, are not afraid of making language mistakes and ready to adopt some of the identity characteristics of another cultural group. According to Veronica [27], these learners can be considered as mastery oriented because they tend to understand failure in terms of lack of effort and always want to improve their performance.

Different learning styles also play an important role in enhancing learners ' motivation in L2 learning. It is found that when learners are given some freedom to choose their preferable ways of learning, they might do better than those who find themselves forced to learn with learning styles that do no suit them. Teachers should be allowed to adapt their programmes with due attention to the objectives of their learners and the needs of the area where they are teaching. Though, this might not always be easy, a concern for the learners' learning styles might be of great help in motivating them to learn.

The existence of power relationships between languages is one of the reasons why people have favourable or unfavourable attitudes towards learning a particular language. Subjects, who select instrumental reasons over integrative ones, often take into consideration the economic and practical advantages of learning a second language. A good example in this respect is the present situation in Romanian schools where learners and the parents, faced with the opportunity of choosing between English and French, generally choose the former as it has become a kind of lingua franca, placing those who are able to use it in a more favourable position than those who are proficient in French. In the same way, members of a minority group may have different attitudes and motivation when learning the language of a majority group than those of 
majority of group members learning a minority language. Here, the case of immigrants is perhaps the most relevant.

Here, we can draw a distinction between two types of motivation; when the only reason for learning is to gain something outside the activity itself such as passing an exam, obtaining financial rewards or pleasing another person, the motivation is likely to be extrinsic or instrumental. It is caused by a combination of external factors and used as a means to obtain something. However, when the purpose of motivation is to enable a learner to communicate with the members of a specific language community, then the motivation is considered as intrinsic or integrative. In order to give a clear image of the intrinsic-extrinsic dichotomy, Spolsky [47] borrows a model from Harter [48] and represents it in a certain way. This representation is shown if Table I.

\begin{tabular}{|c|c|c|}
\hline Intrinsic & Versus & Extrinsic \\
\hline Preference for challenge & vs & Preference for easy work \\
\hline Curiosity / interest & vs & $\begin{array}{l}\text { Pleasing a teacher / getting } \\
\text { grades }\end{array}$ \\
\hline Independent mastery & vs & $\begin{array}{l}\text { Dependence on teacher in } \\
\text { figuring out problems }\end{array}$ \\
\hline Independent judgement & vs & $\begin{array}{l}\text { Reliance on teacher's } \\
\text { judgment about what to do }\end{array}$ \\
\hline Internal criteria for success & vs & External criteria for success \\
\hline
\end{tabular}

This model summarizes that the greater the value the individuals attach to the accomplishment of an activity, the more highly motivated they will be to engage in it and later to put sustained effort until they achieve their goal. This distinction also tells us that both internal and external factors have an important role to play in motivating learners.

\section{IMPLICATION}

Teachers should play their roles as motivators to learners in learning or acquiring L2 because results from both views (intrinsic and extrinsic) indicate that teachers can be influential in affecting learners' motivation and attitudes and in creating a learning community in which learners can study a language with less anxiety. Teachers seemed to play the most important role in shaping the culture of the class. It was the teachers who decided how to use or implement the course materials for the class.

One particular strength of the theory from Gardner [3] is that it originated from and was tested by empirical research and one can clearly feel the assessment-oriented nature of his conceptualisation. The importance of the desire measure the individual's wish to perform the action and the motivational intensity measure that explicitly focuses on motivated behaviour.

According to Gardner [3], a motivated learner can be defined as one who is eager to learn the language, willing to expend effort on the learning activity and willing to sustain the learning activity. The implications of the Gardner's motivation theory in language learning are first it mediates any relation between language attitudes and language achievement. Second, it has a causal relationship with language anxiety and finally it has a direct role in the informal learning context, showing the voluntary nature of the motivated learners' participation in informal L2 learning contexts.

\section{CONCLUSION}

The paper concludes that L2 learners' motivation (intrinsic motivation) and the effect of perceived levels of teachers' commitment (extrinsic motivation) reconfirms that a teacher influences his/her learners' motivation. Besides that, some studies indicate that learners' levels of proficiency may be an important factor which can determine the effectiveness of teaching strategies as a motivator for learners. With regard to the level of proficiency, there are two issues raised with particular importance.

Firstly, the learners at the intermediate level seem to be in the stage of learning English which involves the most challenging in their learning process. They appear to be have weak motivation and view their teachers not as actively as a motivator compared to learners at lower or higher levels of proficiency. This is probably because they have been engaged in English study for a long time and they may have developed a sense of "helplessness" primarily due to the lack of a clear indication of progress, or because they may be overwhelmed by the contents introduced in the course.

Therefore, we can conclude that motivation is a crucial factor in learning the second language and it is influenced by different variables like personality and attitudes of learners, their learning styles and the power relationship between languages. In other words, these variables are possible factors to enhance learners' motivation in L2 learning.

\section{REFERENCES}

[1] R. M. Ryan and E. L. Deci, "Self-determination theory and the facilitation of intrinsic motivation, social development, and well-being," The American Psychologist, vol. 55, no. 1, pp. 68-78, 2000.

[2] R. C. Gardner, Motivation and Second Language Acquisition: The Socio-Educational Model, 1st ed. New York: Peter Lang Publishing, 2010.

[3] R. C. Gardner, Social Psychology and Language Learning: The Role of Attitudes and Motivation, 1st ed. London: Edward Arnold, 1985.

[4] A. Bandura, Self-Efficacy: The Exercise of Control, New York: W. H. Freeman, 1997.

[5] M. Csikszentmihalyi, Flow: The Psychology of Optimal Experience, 1st ed. New York: Harper Perennial, 1991.

[6] A. Walqui. (2000). Contextual factors in second language acquisition. [Online]. Available: http://www.cal.org/resources/digest/0005contextual.html

[7] P. Pintrich and D. Schunk, Motivation in Education: Theory, Research \& Applications, 3rd ed. Englewood Cliffs, New Jersey: Prentice-Hall, 1996.

[8] R. C. Gardner and W. E. Lambert, "Motivational variables in second language acquisition," Canadian Journal of Psychology, vol. 13, no. 4, pp. 266-272, 1959.

[9] E. Ushida, "The role of students' attitudes and motivation in second language learning in online language courses," CALICO Journal, vol. 23 , no. 1 , pp. 49-78, 2005.

[10] R. C. Gardner and P. D. MacIntyre, "A student's contributions to second-language learning. Part II: Affective variables," Language Teaching, vol. 26, no. 1, pp. 1-11, 1993.

[11] K. A. Noels, L. G. Pelletier, R. Clément, and R. J. Vallerand, "Why are you learning a second language? Motivational orientations and self-determination theory," Language Learning, vol. 50, no. 1, pp. $57-85,2000$ 
[12] E. L. Deci and R. M. Ryan, Intrinsic Motivation and Self-Determination in Human Behavior, 1st Ed. New York: Plenum, 1985.

[13] R. J. Vallerand, "Toward a hierarchical model of intrinsic and extrinsic motivation," in Advances in Experimental Social Psychology, M. P. Zanna, Ed. New York: Academic Press, 1997, pp. 271-360.

[14] X. Wu, "Intrinsic motivation and young language learners: The impact of the classroom environment," System, vol. 31, no. 4, pp. 501-517, 2003.

[15] E. Medford and S. P. McGeown, "The influence of personality characteristics on children's intrinsic reading motivation," Learning and Individual Differences, vol. 22, no. 6, pp. 786-791, 2012.

[16] Z. Dornyei, "Motivation and motivating in the foreign language classroom," The Modern Language Journal, vol. 78, no. 3, pp. 273-284, 1994.

[17] T. Tanaka, "Teacher influence on learner motivation," 2010.

[18] Z. Dornyei and E. Ushioda, Teaching and Researching Motivation, 2nd ed. Harlow: Longman, 2011.

[19] H. Sakai and K. Kikuchi, "An analysis of demotivators in the EFL classroom," System, vol. 37, no. 1, pp. 57-69, 2009.

[20] Z. Dornyei, Teaching and Researching Motivation, 1st ed. Harlow: Longman, 2001.

[21] E. Ushioda, "Motivation as a socially mediated process," in Learner Autonomy in the Foreign Language Classroom: Teacher, Learner, Curriculum and Assessment, D. Little, J. Ridley, and E. Ushioda, Eds. Dublin: Authentik, 2003, pp. 90-102.

[22] D. M. Christophel and J. Gorham, "A test-retest analysis of student motivation, teacher immediacy, and perceived sources of motivation and demotivation in college classes," Communication Education, vol. 44, no. 4, pp. 292-306, 1995.

[23] J. Gorham and D. M. Christophel, "Students' perceptions of teacher behaviors as motivating and demotivating factors in college classes," Communication Quarterly, vol. 40, no. 3, pp. 239-252, 1992.

[24] Z. Dornyei, Motivational Strategies in the Language Classroom, 1st ed. Cambridge: Cambridge University Press, 2001.

[25] K. Kikuchi, "Japanese learners' demotivation to study english: A survey study," JALT Journal, vol. 31, no. 2, pp. 183-204, 2009.

[26] V. Jurik, A. Gröschner, and T. Seidel, "Predicting students' cognitive learning activity and intrinsic learning motivation: How powerful are teacher statements, student profiles, and gender?" Learning and Individual Differences, vol. 32, pp. 132-139, 2014.

[27] A. C. S. Veronica, "Motivation in language learning," Annals of the University of Oradea, Economic Science Series, vol. 17, no. 1, pp. $557-562,2008$

[28] M. Finocchiaro and C. Brumfit, A Functional-Notional Curriculum: From Theory to Practice, 1st ed. Oxford, UK: Oxford University Press, 1982.

[29] M. Williams and R. Burden, Psychology for Language Teachers, 1st ed. Cambridge: Cambridge University Press, 1997.

[30] M. Bernaus and R. C. Gardner, "Teacher motivation strategies, student perceptions, student motivation, and English achievement," The Modern Language Journal, vol. 92, no. 3, pp. 387-401, 2008.

[31] K. A. Noels, "New orientations in language learning motivation: Towards a model of intrinsic, extrinsic and integrative orientations," in Motivation and Second Language Acquisition, Z. Dörnyei and R. Schmidt, Eds. Honolulu, HI: University of Hawai's Second Language Teaching and Curriculum Centre, 2001, pp. 43-68.

[32] R. Clement, "Ethnicity, contact and communicative competence in a second language," in Language: Social Psychological Perspectives: Selected Papers from the First International Conference on Social Psychology and Language held at the University of Bristol, England, July 1979, H. Giles, W. P. Robinson, and P. M. Smith, Eds. Oxford: Pergamon, 1980, pp. 147-154.

[33] M. J. Guilloteaux and Z. Dörnyei, "Motivating language learners: A classroom - Oriented investigation of the effects of motivational strategies on student motivation," Tesol Quarterly, vol. 42, no. 1, pp. $55-77,2008$

[34] Z. Dornyei and K. Csizer, "Ten commandments for motivating language learners: Results of an empirical study," Language Teaching Research, vol. 2, pp. 203-229, 1998.
[35] M. Bernaus, A. Wilson, and R. C. Gardner, "Teachers' motivation, classroom strategy use, students' motivation and second language achievement," Porta Linguarum, vol. 12, pp. 25-36, 2009.

[36] J. Kormos, T. Kiddle, and K. Csizér, "Systems of goals, attitudes, and self-related beliefs in second-language-learning motivation," Applied Linguistics, vol. 32, no. 5, pp. 495-516, 2011.

[37] D. Atay and G. Kurt, "The socio-educational model of second language acquisition: The Turkish context," Procedia Social and Behavioral Sciences, vol. 1, no. 2, pp. 3088-3093, 2010.

[38] K. Csizer and Z. Dornyei, "Language learners' motivational profiles and their motivated learning behavior," Language Learning, vol. 55, no. 4, pp. 613-659, 2005.

[39] K. Csizer and J. Kormos, "Modelling the role of inter-cultural contact in the motivation of learning English as a foreign language," Applied Linguistics, vol. 30, no. 2, pp. 166-185, 2009.

[40] J. Kormos, T. Kiddle, and K. Csizer, "Goals, attitudes and self-related beliefs in second language learning motivation: An interactive model of language learning motivation," Applied Linguistics, vol. 32, no. 5, pp. 495-516, 2011

[41] A. E. Wilson, "Interpreting differences in parental encouragement to learn the host language: California and Catalonia compared," Bellaterra: Journal of Teaching and Learning Language and Literature, vol. 5, no. 3, pp. 44-56, 2012.

[42] B. Bartram, "An examination of perceptions of parental influence on attitudes to language learning," Educational Research, vol. 48, no. 2, pp. 211-221, 2006.

[43] A. Morris, M. Lafonataine, F. Pichette, and L. de Serres, "Affective variables, parental involvement and competence among South Korean high school learners of English," Studies in Second Language, vol. 3, no. 1 , pp. $13-45,2013$

[44] Z. Dornyei, "Motivation in action: Towards a process-oriented conceptualisation of student motivation," British Journal of Educational Psychology, vol. 70, pp. 519-538, 2000.

[45] S. R. Jacques, "Preferences for instructional activities and motivation: A comparison of student and teacher perspectives," in Motivation and Second Language Acquisition, Z. Dornyei and R. Schmidt, Eds. Honolulu, HI: Second Language Teaching \& Curriculum Centre, University of Hawaii, 2001, pp. 185-221.

[46] W. Rivers, "Psychology: Linguistics and language teaching," A Forum Anthology, pp. 3-11, 1983.

[47] B. Spolsky, Conditions for Second Language Learning, 1st ed. Oxford, UK: Oxford University Press, 1989.

[48] S. Harter, "The perceived competence scale for children," Child Development, vol. 53, pp. 87-97, 1982.

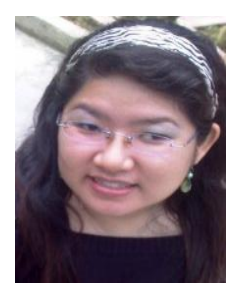

Chiew Fen Ng is a postgraduate student at Universiti Putra Malaysia (UPM). She is currently pursuing her master's degree of applied linguistics at the Faculty of Modern Language and Communication. She also holds a bachelor's degree in computer science from Coventry University. Prior to the pursuit of her postgraduate studies, she served as an educator at Erican Language Centre and Cosmotots for a few years. She has also worked at National Semiconductor as a production executive for a number of years before deciding to venture into the field of education. Her research interests include sociolinguistics, pragmatics, discourse analysis and English for specific purposes. and the other authors may include biographies at the end of regular papers.

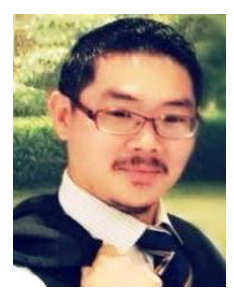

Poh Kiat Ng is a senior lecturer from the Faculty of Engineering and Technology, Multimedia University, Malaysia. He is also a PhD candidate at the Technical University of Malaysia (UTeM). Prior to being an academician, he has worked as a manufacturing engineer in Infineon Technologies and as a process engineer in National Semiconductor. His research interests include ergonomics, biomechanics, knowledge management, total quality management, manufacturing management, engineering education, concurrent engineering, teaching strategies and learning strategies. 